\title{
ON DISCOVERING AND PROFITING FROM THE SENSE OF BELONGING LITERATURE
}

\author{
Dr. Susan PEACOCK \\ Queen Margaret University, UK \\ speacock@qmu.ac.uk
}

\begin{abstract}
A sense of belonging ( $S o B)$ is a recognised and valued concept in education, associated with increased student attainment, improved learners' satisfaction and lowered attrition rates. Some scholars even assert that learners are unable to fulfil the goals of higher education without first having acquired a SoB. I am suggesting that a SoB should be generated purposefully in any online learning environment, to address learners' welldocumented feelings of isolation, marginalisation, alienation and loneliness. I explore a definition of this concept and then summarise what I have found in the work of researchers who consider it important that their learners develop a sense of belonging. Thereafter, I outline the principal features which contribute to a learner's sense of belonging, and what is known of how they are promoted (or frustrated) by institution, course teams or individual tutors. Finally, I indicate the immediate priorities for teachers like myself who wish to promote and evaluate a sense of belonging for their learners in their own context.
\end{abstract}

Keywords: sense of belonging; online learning;

\section{Introduction and explanation}

After having worked with students online for over a decade, I had become aware that those learners who had flourished in their studies appeared to have a distinct connection to the course. Those who had developed significant relationships both with myself as the tutor and with their peers, had also developed in self-confidence, self-esteem and selfefficacy. It was also promising to see their interpersonal and cognitive skills 
and abilities thrive. What was it that did this? Last year I attended a conference where I was fortunate to listen to Thomas (2017) outline her work on Sense of Belonging, and the penny dropped for me.

It is less than two years now since I encountered the term 'sense of belonging'. During a considerable career in teaching, I have been working to generate this sense of belonging on the part of my students, but without knowing that that was what I was doing and without rationalising the elements in my approach which make a positive contribution to this outcome. It has certainly long mattered to me to make my students feel at home, valued and members with me of a class group linked not just by shared educational aims, but by a strong feeling of belonging to a significant learning community. I wanted them to feel a sense of connection. However, I would have been at a loss to pinpoint how I had been doing this. Thomas's talk encouraged me on to organise my thinking.

I started to read recent papers about 'sense of belonging'. I was excited to find this concept effectively and motivatingly summarised, and to some extent given academic status, in the various writings I discovered about students having a sense of belonging. I found myself devouring these writings, quickly finding definitions and clarification of my established intuitive practice. I have been actively sharing that enthusiasm for this formally titled aspect of online pedagogy with my colleagues, my students and others. Now, for this conference I wanted to share that enthusiasm with delegates, hoping that for some I could spread the message I have been discovering about the importance for students, and especially online students, of having a sense of belonging. I am sure that there are others who have already progressed further than I am, and who I hope will be prompted to share their practices and experiences with us all through our conference networking.

\section{Outline}

I open with a clear definition of this concept. Then I summarise what I have found to date in the work of researchers who consider it important that their learners develop a sense of belonging. Thereafter, I outline the principal features which contribute to a learner's sense of belonging, and what is known of how they are promoted (or frustrated) by institution, course teams or individual tutors. By this point, I am aware that many readers will be wondering about the demands on tutors' time; I attempt to address this. Finally, I indicate the immediate priorities for teachers like myself who wish to promote and evaluate a sense of belonging for their learners in their own context. I cite one or two key sources and recommend for your further 
reading a few texts which I have found useful and thought-provoking. If you would like further information, do please contact me.

\section{Definition}

Many definitions of the concept of sense of belonging ( $\mathrm{SoB}$ ) in an educational context have been published. I am attracted to that provided by Goodenow (1993) who described a sense of belonging as comprising feelings of:

being accepted, valued, included, and encouraged by others (teachers and peers) in the academic classroom and of feeling oneself to be an important part of the life and activity of the class. More than simple perceived liking or warmth, it also involves support and respect for personal autonomy and for the student as an individual (p.25).

This highlights two key attributes in the concept. The first involves feelings of being accepted, needed, mattering and valued. The second includes feelings of fitting in, being connected to a group, class, subject or institution or to all of these. Both originate in relationships, and especially in tutor/student relationships.

\section{Sense of belonging and online learning}

Before I devoted much of my continuing professional development to SoB, I had been finding much inspiration in the writings of Garrison, and his followers in Canada. These works address the planning, delivery and impact for online learning programmes centred upon Communities of Inquiry. After listening to Thomas and reading some of her writings, I recalled that Garrison conceives the Community of Inquiry Framework for online education as providing "a collaborative experience, which includes a sense of belonging and acceptance in a group with common interests" (Garrison, 2017 p.35). Having a strong sense of belonging to their institution, their course, their teachers and their peer group, has been rated key to academic success and persistence for online tertiary learners. Strayhorn even maintains that a SoB is essential if higher order outcomes such as understanding and self-actualisation are to be fulfilled. Researchers, especially those in the US such as Freeman, Anderman, \& Jensen in 2007 and Ostermann in 2000, have reported the important link between SoB and 
improved academic engagement and achievement, heightened selfconfidence and self-efficacy.

Online learning can be a lonely activity from the start. Learners new to this experience can easily feel lost. Initial problems for online learners with navigation through a wealth of materials and an accumulation of new types of demand such as online group work can readily generate feelings of anxiety, frustration and of being out of their depth. For many, the very thought of posting their thoughts into an online discussion forum is a daunting and even threatening prospect. Clearly their need for a sense of belonging and of being valued is most important if they are to function confidently in this new learning environment, to flourish in the diverse online educational spaces, and to achieve their personal and professional goals. The researchers who have studied the importance and impact of SoB for online learners provide much insight. Reading these researchers' work has subsequently contributed strongly to the planning of my teaching, to my work as an educational developer, to my own further professional development, and to my eagerness to become engaged in action-research in this field. Amongst these roles, direct online tutoring is the one likely to have the greatest impact, so I should start there.

\section{Promoting a sense of belonging}

As a tutor working within the Community of Inquiry Framework, I follow Garrison in the conviction that I should 'establish a feeling of belonging to the critical community that must develop over time' (Garrison, 2011, p. 32), since that is an 'essential facilitating condition for engagement in critical discourse' (p. 37). As a tutor, I have found that I can promote a sense of belonging by quickly developing open communications with and between learners so that they gain a sense of being meaningfully connected to and engaged their peers, and with me as their tutor. My colleague Cowan and I have established that trust amongst peers and with their tutor is an essential foundation for effective online learning. Cowan (2013) has written of this elsewhere. Trust originates in, and is then nurtured by, a sense of belonging. Any online tutor should therefore set out immediately to establish a feeling by learners of being welcomed into a community where trust features naturally (Garrison, 2011; pp. 88-89). I have found in my own experience that the nature, type and tones of the online tutor's interactions with learners can create a trusting, caring and encouraging environment, featuring open communication. This can be achieved by: 
- Contacting learners as soon as possible, modelling frank, informal and helpful interactions as a norm

- Anticipating and resolving learners' affective needs

- Unobtrusively facilitating development of the abilities needed for online learning

- Showing awareness of learners' current concerns and of their successes

- Frequently nudging learners towards constructive interaction with peers.

\section{Institutional and course team initiatives}

Important as the contribution of tutoring can be to the development of learners' sense of belonging, it is not a first priority - chronologically. For efforts to establish a sense of belonging should begin before any learners are enrolled, in the creative planning of the arrangements made for their studying. The institution and course team should plan to immediately and effectively demonstrate a genuine concern to encourage and enable learners to engage effectively with the demands of their course, and to do so as they take their first steps.

Online learners will not be able to cope effectively with their cognitive activity unless they already have a clear impression of the support services that will be available to them. Preferably, these should be mapped in an informative, though not a directive, way. For learners need to identify and access the sources from which they can valuably enrich their course-related understandings in their chosen directions and in their own individual ways. Unfortunately, online learners nowadays often report problems with navigation, with searching ineffectively for services, and in needing better and more supportive advice and assistance. Such problems can inhibit learning and generate feelings of disenchantment with the course and with the institution. Support services should be readily available and plan to respond to all inquiries in a helpful, warm and welcoming manner.

Planning to embody a sense of belonging should go beyond arranging for such opening encounters. Online learners who are engaged in meaningmaking will find that process enhanced in terms of their sense of belonging by the existence and use of two noteworthy features in their programme. Firstly, they should have opportunities for relevant groupwork in which learners can work together to explore their emergent understandings through planned interactions within the community. Secondly, their learning will be enhanced (but not directed) by the structuring of effective loops in the 
programme providing constructive peer feedforward, which will also nurture a sense of belonging to the community.

Institutions and course teams who aim to engender a sense of belonging on the part of online students should therefore

- Structure course plans to ensure that support services are ready to provide friendly and caring assistance and advice at the outset

- Structure programmes to build a sense of belonging by featuring appropriate socio-constructivist activities

- Arrange peer-interaction to provide rapid constructive collegial feedforward, and nurture a meaningful sense of belonging to a community

- Incorporate informed tutor feedback showing interest in work in hand, as well as offering constructive comment

- Show each tutor's immediate awareness and appreciation of valuable issues and concepts emerging in ongoing community learning activity

- Support learner engagement in activities for both individuals and groups, leading to a sense of worth and mattering, and promoting sense of belonging

- Evaluate the arrangements made to promote a sense of belonging and enhance accordingly.

\section{How sustainable is it to promote a sense of belonging?}

Cowan and I are currently involved in finalising a paper whose provisional title, at present, is: Promoting virtual relationships to engender a sense of belonging online. We are trying to offer practical suggestions for academics. We attempt to include nothing which we ourselves would not undertake in the normal course of our teaching duties, and little if anything which we would be reluctant to suggest to our colleagues. Many of our suggestions entail a change in emphasis or style and a few demands much in the way of additional commitment. Consequently, we are witness to our conviction that promoting a sense of belonging need not be other than sustainable.

\section{Action-researching a sense of belonging}

I have found much in the SoB literature to inspire me; I have also emerged from my reading with important and unanswered questions. Three 
of the most immediate, for me, my colleagues in our own courses and Cowan are:

1. What experiences in my online courses generate a sense of belonging for my students - and what experiences have the contrary effect? Why has this been so for the learners concerned?

2. What effect does having, or not having, a sense of belonging has on learning behaviour and learning achievement for my students?

3. What can I do to further promote a sense of belonging on the part of my students?

Even as I have been writing this conference paper, I was receiving encouraging reports of questionnaire responses by students currently studying on courses offered by myself and three colleagues. We tutor have combined as action-researchers to seek individual answers in our own context to these three questions, centred on critical incidents with positive or negative impact. The second stage of this inquiry will take the form of carefully planned interviews by an external researcher with some of the responding students.

\section{What reading do I recommend?}

I went on to read the report by Thomas soon after I had heard her speak; I warmly commend this report to you:

Thomas, L. (2012). Building student engagement and belonging at a time of change in higher education. London: Paul Hamlyn Foundation. Retrieved from https://www.heacademy.ac.uk/knowledgehub/building-student-engagement-and-belonging-higher-educationtime-change-final-report.

I found myself returning to Strayhorn again and again. I have warmed to his care and concern for the underprivileged who so need a sense of belonging when they venture into tertiary education:

Strayhorn, T. (2012). College students' sense of belonging: A key to educational success for all students. Oxon, UK: Routledge.

Garrison is rightly regarded as the guru of Community of Inquiry learning online. His book contains more than that, and implicitly assumes 
that our online learners should have a sense of belonging. I recommend both editions of his seminal work:

Garrison, D. R. (2011). E-learning in the 21st century: A Community of Inquiry framework for research and practice (2nd Ed.). New York: Routledge

Garrison, D. R. (2017). E-learning in the 21st century: A Community of Inquiry framework for research and practice (3rd ed.). New York: Routledge

I have also referenced the definition by Goodenow in 1993. I highly recommended to you her seminal work in the early 1990s with adolescents:

Goodenow, C. (1993). Classroom belonging among early adolescent students: Relationships to motivation and achievement. The Journal of Early Adolescence, 13(1), 21-43.

John Cowan has long campaigned for the importance of trust in tutor/student relationships. The principles he outlined regarding facilitating reflective journalling have widespread application:

Cowan, J. (2013) Facilitating reflective journaling - personal reflections on three decades of practice. Journal of Learning Development in Higher Education. Issue 5, March. ISSN: 1759-667X

Finally, I have been influenced by the significant work in the United States, exploring the importance of $\mathrm{SoB}$ for students who perceive themselves as marginal to campus life, such as learners who are nontraditional according to class, race, ethnicity, sexual identity, income and disability. I would recommend:

Hausmann, L. R. M., Ye, F., Schofield, J. W., \& Woods, R. L. (2009). Sense of belonging and persistence in white and African American first-year students. Research in Higher Education, 50(7), 649-669.

Osterman, K. (2000). Students' need for belonging in the school community. Review of Educational Research, 70(3), 323-367. 
Vaccaro, A., Daly-Cano, M., \& Newman, B. M. (2015). A sense of belonging among college students with disabilities: An emergent theoretical model. Journal of College Student Development, 56(7).

\section{Conclusion}

Throughout my life, I know that the presence, or absence, of a sense of belonging in professional settings makes a significant difference to my own motivation and commitment, professionally and personally. For my students it is something that I strive to promote in all my interactions and in my friendships both within and outwith tertiary education.

\section{Acknowledgements}

This paper, and my current research explorations, would not have been possible without my mentor, my guide and my special friend, Professor John Cowan. Whilst it is not possible for him to join with us at the conference, he has been a guiding light throughout my doctoral work and now its continuation in our collaborative research enterprises especially Sense of Belonging. He is an inspiration; his passion for his students and his commitment to excellence in learning and teaching cannot be matched.

\section{References}

Cowan, J. (2013). Facilitating reflective journaling - personal reflections on three decades of practice. Journal of Learning Development in Higher Education. Issue 5, March. ISSN: 1759-667X

Garrison, D. R. (2011). E-learning in the 21st century: A Community of Inquiry framework for research and practice (2nd Ed.). New York: Routledge

Garrison, D. R. (2017). E-learning in the 21st century: A Community of Inquiry framework for research and practice (3rd ed.). New York: Routledge

Goodenow, C. (1993). Classroom belonging among early adolescent students: Relationships to motivation and achievement. The Journal of Early Adolescence, 13(1), 21-43.

Hausmann, L. R. M., Ye, F., Schofield, J. W., \& Woods, R. L. (2009). Sense of belonging and persistence in white and African American first-year students. Research in Higher Education, 50(7), 649-669.

Osterman, K. (2000). Students' need for belonging in the school community. Review of Educational Research, 70(3), 323-367. 
Strayhorn, T. (2012). College students' sense of belonging: A key to educational success for all students. Oxon, UK: Routledge.

Thomas, L. (2012). Building student engagement and belonging at a time of change in higher education. London: Paul Hamlyn Foundation. Retrieved from https://www.heacademy.ac.uk/knowledge-hub/building-studentengagement-and-belonging-higher-education-time-change-final-report.

Vaccaro, A., Daly-Cano, M., \& Newman, B. M. (2015). A sense of belonging among college students with disabilities: An emergent theoretical model. Journal of College Student Development, 56(7). 